\title{
Editorial
}

\section{Plus ça change...} 'Plus ça change, plus c'est la même chose (The more
things change, the more they stay the same)'

Alphonse Karr, Les Guêpes 1849 (Knowles, 2001)

The founding members of the Nutrition Society (NS) realised that 'the value of its proceedings would be enhanced by their reaching a wider audience than that which actually participated in its meetings' and 'the question arose of publication with the object of placing the Proceedings at the disposal of an audience outside the membership of the Society' (Nutrition Society, 1944). It is probably safe to assume that the aspirations of those members have been exceeded beyond their wildest expectations with the recent completion of the digitisation of all the back issues of Proceedings of the Nutrition Society (PNS; Original Communications (OC) and full papers). Contents since 1944 should be freely available to all in 2007. As noted previously, $P N S$ provides an official record of the scientific meetings held by the NS and acts as an aide memoir for those present at meetings. For many researchers giving an OC at a NS meeting is their first public presentation and/or the abstract subsequently published will be the first time authors see their name in print in a scientific journal (Goldberg \& Seal, 2002). Even for more experienced presenters and authors, a NS meeting and PNS are their first exposure to an expert nutrition audience. Ever since the introduction, in 1989, of the now familiar format of the annual summer meeting, the Programmes Committee has worked very hard to achieve a balance at NS meetings to facilitate and encourage those at an early stage in their career and international experts to present cutting-edge research and wider ranging symposia and plenary presentations. Attempting to please everyone within the constraints of a practical number of parallel sessions remains a challenge. The aims of these endeavours are successful conferences and good-quality and useful OC and highlycited full papers in PNS. The most recent impact factor for $P N S$ is 2.649 and it ranks 10th of fifty-three nutrition and dietetics journals worldwide.

Journal Editors and the nutrition community as a whole have a duty to 'keep our houses in order' (Margetts, 2006), and that if serious concerns about any publication arise at any time, then after appropriate investigation, action is swiftly taken to remedy this situation. Whilst matters of probity have always applied to NS journals, these are probably most apparent to delegates and presenters at actual NS meetings. Presenters and co-authors should expect to be thoroughly questioned and have to deal with any matters of clarification, concerns or queries at all stages of the publication process: before acceptance for presentation; immediately after presentation; at the editorial desk; during expert review of full papers; even years after publication (see Nutrition Society, 2006).

As has also been noted previously (Younger, 2000, 2001), many visual and behind the scenes changes and changes in procedures have occurred to $P N S$ in recent years. This list is still being added to. For example, the appointment of a Deputy Editor in 2003 and Assistant Editor in 2005 and a cover redesign in 2005. The contents of PNS are now free access to all after 1 year, and full papers from symposia are published online ahead of print and thus available to subscribers as soon as the final version is ready, rather than having to wait for publication in a hard copy of the journal. At the 2006 AGM approval was granted to publish the $\mathrm{OC}$ electronically only. Thus, in 2007 the vast majority of members and subscribers will no longer receive hard copies of issues $\mathrm{A}$ and $\mathrm{B}$ of PNS. However, this change does not mean a downgrading of the status of OC. The same degree of rigour will still be applied to ensure that those OC presented at meetings and subsequently accepted for online publication are of the highest standard and the style and format will be unchanged. There are forthcoming editorial changes. Professor Jamie Newbold (Deputy Editor since 2003) takes over in January 2007 and Dr Colette Kelly will succeed him as Deputy Editor. At the time of writing we are in the process of selecting a new Assistant Editor. The most recent addition to the list of changes is a change of publisher. Changes in their business plans entailed CABI selling the titles they publish. So, after ten very productive years of publishing with CABI, PNS is once again being published by Cambridge University Press.

When I succeeded Dr Kate Younger as PNS Editor in 2001, she wished me 'happy hunting' (Younger, 2001). Like her, I have now enjoyed 5 years of reading manuscripts encompassing a multitude of techniques and subject areas on all aspects of nutrition science. Little did I think that when I submitted, then presented and had published my first OC almost exactly 20 years ago (Goldberg et al. 1987) that I would one day have the honour and privilege of being the Editor of PNS. I would like to thank the NS Publications Staff, especially Christine Hughes, Asha Thiruchelvam and Claire Goodstein, and the Honorary Publications Officer, Kate Younger, for their support, advice and patience, Katy Christomanou (CABI and Cambridge University Press), the Meetings Organiser, Liz Costin, members of the Programmes Committee and local organisers of conferences, Jamie Newbold and, of course, the many authors of full papers and OC for their contributions.

\author{
G. R. Goldberg \\ Honorary Editor \\ Proceedings of the Nutrition Society \\ Gail.Goldberg@mrc-hnr.cam.ac.uk
}




\section{References}

Goldberg GR, Davies HL, Murgatroyd PR \& Prentice AM (1987) Overnight metabolic rate in men and women. Proceedings of the Nutrition Society 46, 118A.

Goldberg GR \& Seal CJ (2002) PNS - still sparkling after 60 years (editorial). Proceedings of the Nutrition Society 61, 1-2.

Knowles E (2001) Oxford Concise Dictionary of Quotations, 4th ed. Oxford: Oxford University Press.

Margetts B (2006) Stopping the rot in nutrition science. Public Health Nutrition 9, 169-173.
Nutrition Society (1944) Foundation of the Nutrition Society. Proceedings of the Nutrition Society 1, 1-6.

Nutrition Society (2006) Retraction of Curtis et al. Effects of $n-3$ fatty acids on cartilage metabolism. Proceedings of the Nutrition Society (2002), 61, 381-389.

Younger KM (2000) Proceedings of the Nutrition Society: 2000 and beyond. Proceedings of the Nutrition Society 59. $1-2$.

Younger KM (2001) A new leaf. Proceedings of the Nutrition Society 60, 1-2. 